\title{
Asiatic acid inhibits proliferation, migration and induces apoptosis by regulating Pded4 via the PI3K/Akt/mTOR/p70S6K signaling pathway in human colon carcinoma cells
}

\author{
YAJUAN HAO $^{1 *}$, JIAWEI HUANG $^{1 *}$, YUN MA $^{2 *}$, WANCHENG CHEN ${ }^{3}$, QIN FAN $^{1}$, \\ XUEGANG SUN $^{1}$, MENG SHAO $^{1 *}$ and HONGBING CAI ${ }^{1 *}$
}

\author{
${ }^{1}$ Department of Traditional Chinese Medicine, Southern Medical University; ${ }^{2}$ Department of Pharmacy, Nanfang Hospital \\ of Southern Medical University; ${ }^{3}$ Cancer Research Institute, Southern Medical University, \\ Guangzhou, Guangdong 510515, P.R. China
}

Received January 5, 2016; Accepted May 25, 2017

DOI: $10.3892 / \mathrm{ol} .2018 .8417$

\begin{abstract}
Previous studies have demonstrated that asiatic acid (AA), the major component of Centella asiatica, is able to meditate cytotoxic and anticancer effects on various types of carcinoma cells. In order to investigate the molecular mechanism that underlies the antitumor effect of AA, the present study investigated the effects of AA on proliferation, migration and apoptosis of SW480 and HCT116 colon cancer cells. Viability and changes in cell morphology in the cells were assessed by MTT assay and transmission electron microscopy, respectively. Colony formation analysis was used to observe proliferation of the single cell, and migratory ability of the cells was assessed by performing Transwell migration assay. Hoechst 33342 nuclear staining and flow cytometry were used to assess apoptosis in colon carcinoma cells. The expression of proteins associated with the phosphoinositide 3-kinase (PI3K)/protein kinase B (Akt)/mammalian target of rapamycin (mTOR)/p70S6K signaling pathway and epithelial-mesenchymal transition (EMT) marker were analyzed by western blotting. The present study revealed that proliferation and migration of colon carcinoma cells were inhibited by AA in a dose-dependent and time-dependent manner. Numerous apoptotic bodies were observed, and $\mathrm{G}_{2} / \mathrm{M}$ and $\mathrm{S}$ phase progression were delayed in colon cancer cells treated with AA, but not in the control group. A number of phosphorylated
\end{abstract}

Correspondence to: Professor Hongbing Cai or Mrs Meng Shao, Department of Traditional Chinese Medicine, Southern Medical University, 1063 Southern Shatai Road, Guangzhou, Guangdong 510515, P.R. China

E-mail: 1043213724@qq.com

E-mail: sm326111@sina.com

${ }^{*}$ Contributed equally

Key words: asiatic acid, programmed cell death protein 4, colon carcinoma, migration, apoptosis proteins, including PI3K, Akt $\left(\mathrm{Ser}^{473}\right)$, mTOR, ribosomal protein S6 kinase (p70S6K) downregulated, while the expression of Pdcd4 was upregulated following treatment with AA. Additionally, AA affects expression of EMT markers in a dose-dependent manner. On the basis of these results, it was concluded that AA inhibited proliferation, migration and induced apoptosis of colon cancer cells by regulating Pdcd4 via the PI3K/Akt/mTOR/p70S6K signaling pathway. These observations suggest that AA may be a potential therapeutic agent for the treatment of colon carcinoma.

\section{Introduction}

Colorectal cancer (CRC) is one of the most common types of cancer worldwide (1). The changes in the Chinese diet and lifestyle have contributed to CRC in becoming the third leading cause of cancer mortality in China (2). Despite recent advances in the surgical treatment, chemoprevention has emerged as an indispensable option for the treatment of CRC (3). The poor prognosis of patients with CRC is primarily due to primary tumor spread and metastasis (4). Therefore, cancer metastasis is one of the important causes of mortality in patients with CRC (5).

Plant-derived compounds are a major source for cancer therapy. Triterpenoids have attracted much attention for their effective antitumor activities. Asiatic acid (AA; $2 \alpha$, $3 \beta, 23$-trihydroxy-12-ursen-28-oic acid, $\left.\mathrm{C}_{30} \mathrm{H}_{48} \mathrm{O}_{5}\right)(4,6,7)$, a naturally occurring pentacyclic triterpenoid, is present in a variety of plants, including Centella asiatica, Purnella vulgaris, Nepeta hindostana, Eucalyptus perriniana and Psidium guajava. AA was primarily used as a dermatological topical agent to prevent ultraviolet A-mediated photo-aging and wounding healing (8). Previous studies suggested that AA possessed a wide range of pharmacological properties, including antihepatofibric, neuroprotective, anti-inflammatory, anti-diabetic and antitumor activities (9). As for antitumor effect, AA was reported to induce apoptosis in hepatic and breast cancer cell lines and other tumor cells $(10,11)$. The efficacy of AA was possibly attributed to the inhibition of nuclear factor- $\mathrm{\kappa B}, \mathrm{p} 38$ mitogen-activated protein kinase and 
extracellular signal-regulated kinase, as well as the change of $\mathrm{Bcl}-2$ and caspase family proteins. Despite the aforementioned widely described antitumor properties, further studies are required to investigate the anti-metastatic potential of AA and to investigate the molecular mechanisms of apoptosis induction and metastasis inhibition.

In the present study, apoptosis and antitumor effects of AA on human colon cancer cells (SW480 and HCT116), was evaluated, and this revealed the role of phosphoinositide 3-kinase (PI3K)/protein kinase B (Akt) signaling pathway in the underlying molecular mechanism.

\section{Materials and methods}

Materials. RPMI-1640 with 10\% heat-inactivated fetal bovine serum (FBS) were purchased from Biological Industries (Kibbutz Beit-Haemek, Israel). Rapamycin was purchased from Selleck Chemicals (Houston, TX, USA). Antibodies were purchased from Cell Signaling Technology (Danvers, MA, USA). Hoechst 33342 dye was purchased from Sigma-Aldrich (Merck KGaA, Darmstadt, Germany). Fluorescein isothiocyanate (FITC)-labeled Annexin V and propidium iodide (PI) were purchased from Nanjing KeyGen Biotech. Co., Ltd. (Nanjing, China).

AA samples. AA previously isolated from the urban of Centella asiatica (Umbelliferae) was used (12). These compounds used for the present study were analyzed by high-performance liquid chromatography and were $>97 \%$ pure. AA was dissolved in dimethyl sulfoxide (DMSO; Sigma-Aldrich; Merck KGaA) to make a stock solution at a concentration of $1 \mathrm{mg} / \mathrm{ml}$, which was further diluted to the appropriate concentration with culture medium prior to each experiment.

Cell line and cell culture. The human colon cancer cells (SW480 and HCT116) were obtained from the Cancer Research Institute, Southern Medical University (Guangzhou, China). The cells were incubated in RPMI-1640 added with either $10 \%$ heat-inactivated FBS (both from Biological Industries), at $37^{\circ} \mathrm{C}$ in a humidified atmosphere containing $5 \% \mathrm{CO}_{2}$.

Cell viability assay. Cell viability was measured by MTT assay; cells without AA treatment were used as the control group. (Sigma-Aldrich; Merck KGaA). Subsequently, the cells $\left(3 \times 10^{3}\right)$ were seeded into 96-well plates (Nest Biotechnology Co., Ltd., Wuxi, China) and allowed to adhere following culture. After the cells were treated with 0, 10, 20, 30, 40 and $50 \mu \mathrm{g} / \mathrm{ml}$ of AA for various time-points from 24 to $72 \mathrm{~h}$. A total of $15 \mu \mathrm{l}$ MTT solution was added to each well for an additional $4 \mathrm{~h}$ at $37^{\circ} \mathrm{C}$, and $150 \mu \mathrm{l}$ DMSO was also added into each well, followed by incubation at $37^{\circ} \mathrm{C}$ for $10 \mathrm{~min}$ with gentle shaking. The absorbance value of each well was measured at $490 \mathrm{~nm}$ using a spectrophotometer (ELx800; BioTek Instruments, Inc., Winooski, VT, USA). The experiments were performed in triplicate.

Assessment of cell morphology. Abnormalities in cell morphology were observed using an optical microscope. Briefly, $5 \times 10^{5}$ cells were seeded into each well of 6 -well plates (Nest Biotechnology Co., Ltd.) and allowed to adhere following culture. Subsequently, the cells were treated with 0 , 15 and $25 \mu \mathrm{g} / \mathrm{ml}$ of AA for $24 \mathrm{~h}$ at $37^{\circ} \mathrm{C}$, and observed under an optical microscope (magnification, x100; Nikon TE2000; Nikon Corporation, Tokyo, Japan).

Colony formation assay. Cell proliferation was detected by colony formation assay. The cells were seeded into 6-well plates (Nest Biotechnology Co., Ltd.) at $2 \times 10^{2}$ cells/well. Following incubation for $24 \mathrm{~h}$ at $37^{\circ} \mathrm{C}$, the medium was replaced by fresh medium with 0,15 and $20 \mu \mathrm{g} / \mathrm{ml}$ AA respectively. When there were visible colonies, incubation was stopped and the cells were stained. The number of colonies was under an optical microscope.

Migration assay. For migration assay, $1 \times 10^{2}$ cells in $200 \mu 1$ RPMI-1640 were seeded into upper Transwell chamber with a $8.0-\mu \mathrm{m}$ pore polycarbonate membrane insert (Nest Biotechnology Co., Ltd.). RPMI-1640 (600 $\mu$ l) with 10\% FBS was added into the lower chamber as a chemoattractant. After the cells were incubated for $8 \mathrm{~h}$ at $37^{\circ} \mathrm{C}$, the insert was washed with PBS, and the cells on the upper surface of the insert were gently removed by a cotton swab. The cells adhered to the lower surface were fixed by methanol, stained using $0.1 \%$ crystal violet at room temperature for $20 \mathrm{~min}$ and counted under an optical microscope in 6-8 predetermined fields. For each experiment, three independent filters were analyzed.

Analysis of apoptosis. The cells were distributed into control and treatment groups with AA at 0,15 and $20 \mu \mathrm{g} / \mathrm{ml}$ for $24 \mathrm{~h}$. Following washing with PBS for 1-2 times, $5 \mu \mathrm{g} / \mathrm{ml}$ Hoechst 33342 dye was added to the cells. The cells were subsequently incubated in the dark for $5 \mathrm{~min}$ at room temperature. Then, the cells were observed with a fluorescence microscope (Nikon TE2000; Nikon Corporation) and were captured at $350 \mathrm{~nm}$ (excitation) and $460 \mathrm{~nm}$ (emission).

For analysis of apoptotic rate, flow cytometry (BD Biosciences, Franklin Lakes, NJ, USA) was used. Each cell line was maintained at a density of $2 \times 10^{5}$ cells in 6 -well plates. Following treatment with AA, the cells were harvested, rinsed with ice-cold PBS, and were treated for 30 min with FITC-labeled Annexin V and PI (Nanjing KeyGen Biotech. Co. Ltd.) for $10 \mathrm{~min}$ at room temperature in the dark. Binding buffer $(400 \mu \mathrm{l})$ was added to each tube according to the supplier's protocols, and the cells were analyzed with a flow cytometer within $1 \mathrm{~h}$.

The cells were distributed into 6-well plates, and each cell group had three wells. Following incubation for $12 \mathrm{~h}$ at $37^{\circ} \mathrm{C}$, the cells were treated with AA from 0 to $25 \mu \mathrm{g} / \mathrm{ml}$, respectively. To evaluate the DNA content, the nuclei were fixed in methanol, stained with $15 \mu \mathrm{g} / \mathrm{ml}$ of 4, 60-diamidino-2-phenylindole and $100 \mu \mathrm{g} / \mathrm{ml}$ DNase free RNase A for $30 \mathrm{~min}$ at $37^{\circ} \mathrm{C}$, rinsed twice with PBS. The DNA content of labeled cells was analyzed using fluorescence-activated cell sorting cytometry assay (BD Biosciences). All experiments were performed in triplicate.

Western blotting. The cells were harvested and lysed. $20 \mu \mathrm{g}$ of protein/lane was separated by $10 \%$ SDS PAGE and transferred to polyvinylidene fluoride (PVDF) membranes. The 
A

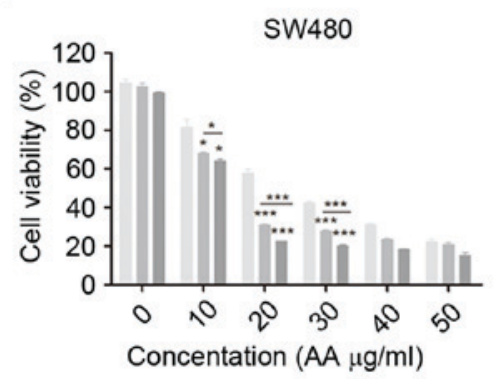

B

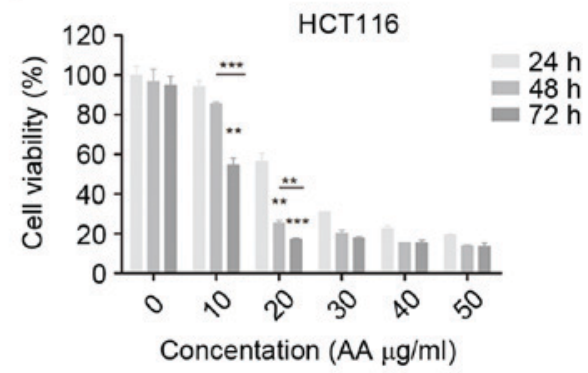

C

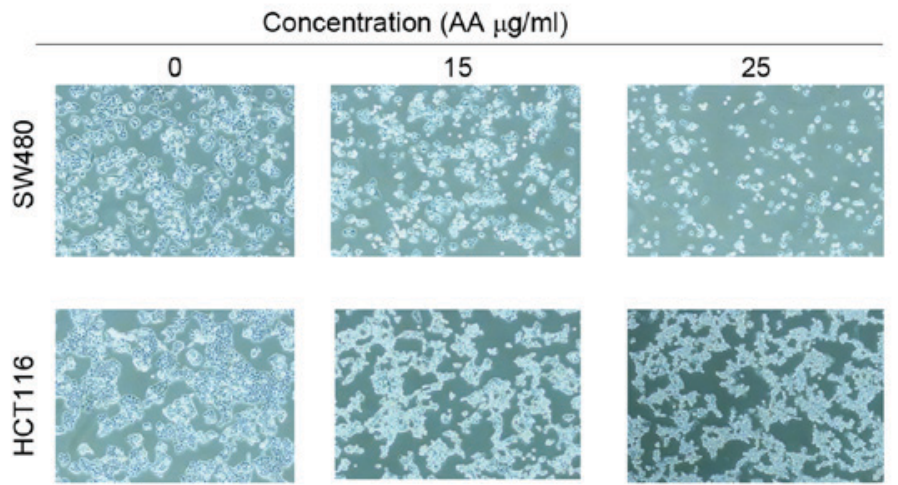

Figure 1. In vitro survival studies of SW480 and HCT116 cells treated with asiatic acid. (A) SW480 and (B) HCT116 cells. Viability of SW480 and HCT116 cells treated with asiatic acid as determined by MTT assay. The viability of SW480 and HCT116 cells was directly proportional to the absorbance at a wavelength of $490 \mathrm{~nm}$. Cell survival was time- and dose-dependent. Error bars represent the standard error of the mean. ${ }^{*} \mathrm{P}<0.05$, ${ }^{* *} \mathrm{P}<0.01,{ }^{* * *} \mathrm{P}<0.001$. (C) $\mathrm{Optical}$ microscope showed different changes in cell morphology in the three treatment groups $(0,15$ and $25 \mu \mathrm{g} / \mathrm{ml})(\mathrm{magnification}, \mathrm{x} 100)$. AA, asiatic acid.

membranes were incubated with the primary antibodies (all rabbit polyclonal antibodies were used at dilution, 1:1,000) including anti-epithelial (E-) cadherin (catalog no. 2500), anti-neural (N-) cadherin (catalog no. 13116), anti-vimentin (catalog no. 12020), anti-phosphorylated (-p) PI3K (catalog no. 3811), anti-PI3K (catalog no. 3821), anti-p Akt (Ser ${ }^{473}$; catalog no. 5012), anti-Akt (catalog no. 4059), anti-p-mammalian target of rapamycin (mTOR; catalog no. 2974), anti-mTOR (catalog no. 2972), anti-p-p70S6K (catalog no. 9205), anti-p70S6K (catalog no. 9202), anti-programmed cell death 4 (Pdcd4; catalog no. 9535S), anti- $\beta$-actin (catalog no. 12620S) and anti-GAPDH (catalog no. 2118S) (all purchased from Cell Signaling Technology, Inc.) overnight at $4^{\circ} \mathrm{C}$, until they were blocked with $5 \%$ non-fat dried milk for $1 \mathrm{~h}$ at room temperature. Then, the immunoreactive bands were visualized by enhanced chemiluminescence using horseradish peroxidase-conjugated immunoglobulin $\mathrm{G}$ secondary antibodies (anti-rabbit; catalog no. 7074P2; dilution, 1:10,000; Cell Signaling Technology, Inc.). The bands were visualized by using an ECL western blot kit (Kangwei Biotech Co., Ltd., Beijing, China). The images were captured with ChemiDoc $^{\mathrm{TM}} \mathrm{CRS}$ and Molecular Imager (Bio-Rad Laboratories, Inc., Hercules, CA, USA).

Statistical analysis. All data are expressed as the mean value \pm standard error from at least three independent experiments. The comparisons of different groups were performed using Student's t-test and one-way of variance (ANOVA). Statistical analyses were performed with the SPSS 13.0 statistical software package (SPSS Inc., Chicago, IL, USA). All statistical tests were two-sided, and $\mathrm{P}<0.05$ was considered to be statistically significant.

\section{Results}

Inhibition of viability of colon carcinoma cells by AA. MTT assay was used to determine the effects of AA on the viability of SW480 and HCT116 cells. The cells were treated with various concentrations of AA $(0-50 \mu \mathrm{g} / \mathrm{ml})$ for 24,48 , and $72 \mathrm{~h}$. AA significantly inhibited the growth of SW480 and HCT116 cells in a dose- and time-dependent manner (Fig. $1 \mathrm{~A}$ and $\mathrm{B} ; \mathrm{P}<0.05$, $\mathrm{P}<0.01, \mathrm{P}<0.001)$. Therefore, various concentrations $(15,20$, and $25 \mu \mathrm{g} / \mathrm{ml}$ ) of AA were selected for subsequent studies.

AA alters the morphology of colon carcinoma cells. The cells were treated with AA at 15 and $25 \mu \mathrm{g} / \mathrm{ml}$ for $24 \mathrm{~h}$. The cells in the control groups grew markedly, while the cells in the drug-treated groups became small and pyknotic, and the cytoplasm was condensed. The cell organelles in the AA-treated groups were swollen, which confirmed that AA had cytotoxic effects on human colon carcinoma cells (Fig. 1C).

AA inhibits proliferation and colony formation of colon carcinoma cells. Colony formation of SW480 and HCT116 cells was inhibited by AA treatment (Fig. 2A). As expected, these cell lines treated with AA presented markedly reduced cell growth and colony formation compared with the control cell lines. The number of colonies treated with AA in groups significantly was reduced, which indicated that proliferation of single cells was also decreased.

AA reduces migration of colon carcinoma cells. To gain an insight into the role of AA in migration and tumorigenesis of SW480 and HCT116 cells, the Transwell migration assay was 
A
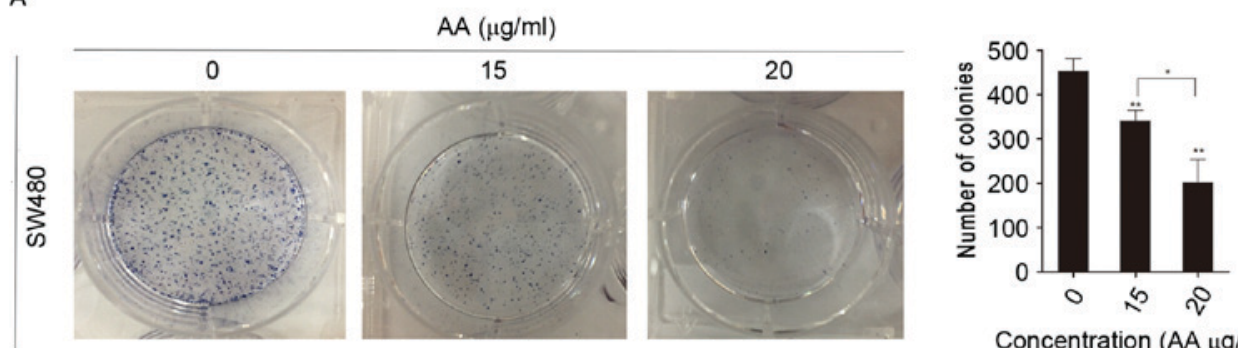

Concentration (AA $\mu \mathrm{g} / \mathrm{ml}$ )
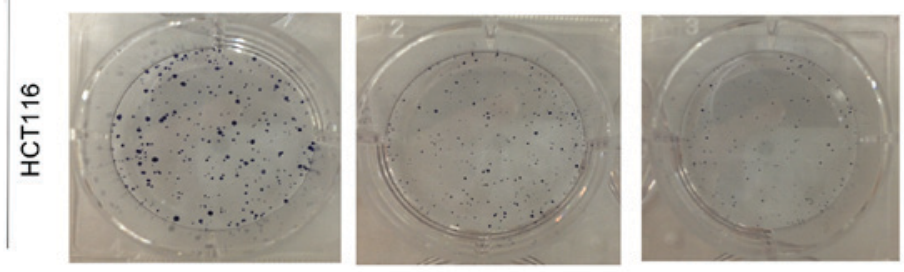

SW480

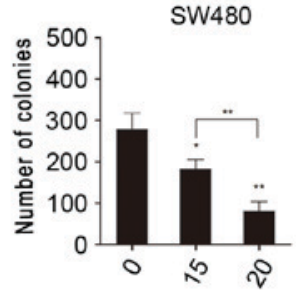

B
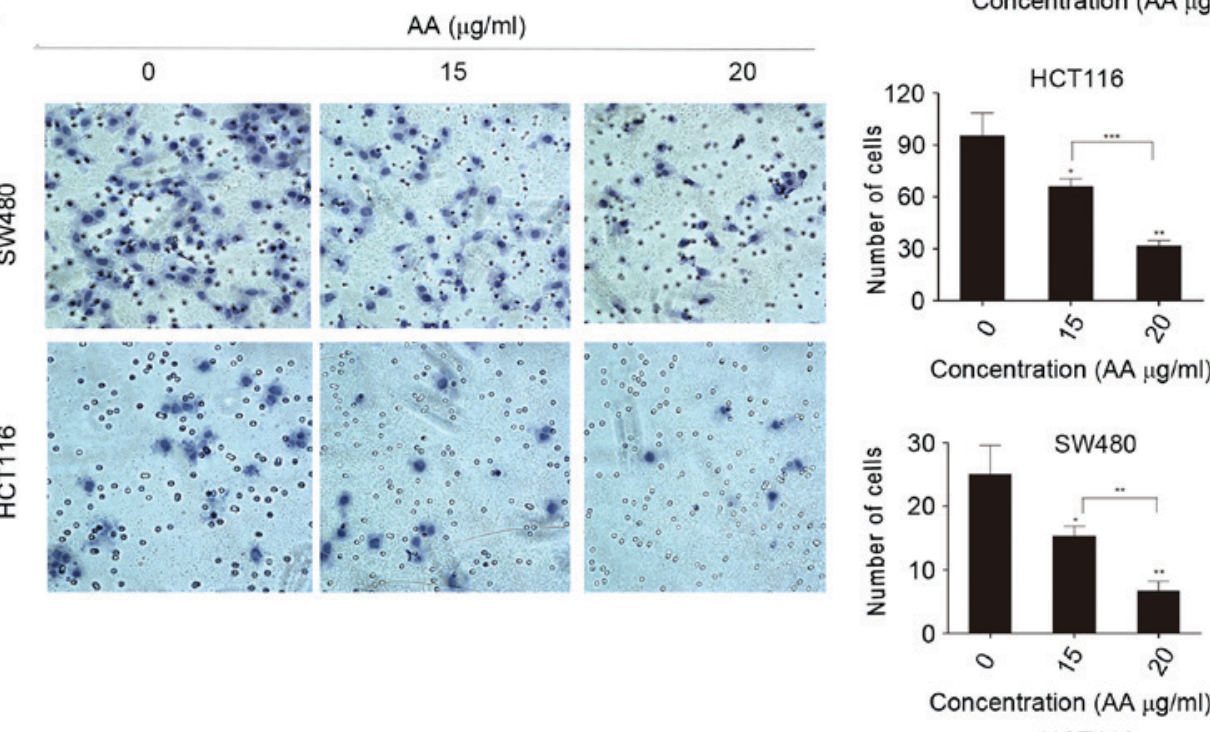

HCT116

Figure 2. In vitro functional studies of AA in SW480 and HCT116 cells. (A) AA inhibited the colony formation of colon carcinoma cells. (B) AA reduced migration of SW480 and HCT116 cells significantly (magnification, $\mathrm{x} 100$ ). All results are expressed as the mean \pm standard error. ${ }^{*} \mathrm{P}<0.05,{ }^{* * *} \mathrm{P}<0.01,{ }^{* * * *} \mathrm{P}<0.001$ vs. control. AA, asiatic acid.

performed (Fig. 2B). It was demonstrated that the number of cells migrated in AA-treated groups was significantly reduced compared with the control. Together, the findings suggest that AA may reduce the migration of SW480 and HCT116 cells. Additionally, the number of SW480 cells migrated in the control group was higher compared to the number in the HCT116 control group. This result indicated that the migratory abilities of SW480 and HCT116 cells were different.

AA induces apoptosis of colon carcinoma cells. To elucidate the underlying mechanism of apoptosis in colorectal carcinoma cells, whether AA is able to induce apoptosis in colon carcinoma cells was investigated by nuclear staining with Hoechst 33342.

Cytoplasmic agglutination, which is a characteristic of active apoptosis, was observed in SW480 and HCT116 cells, which have been treated for $24 \mathrm{~h}$ with 15 and $25 \mu \mathrm{g} / \mathrm{ml} \mathrm{AA}$. Cytoplasmic agglutination was not observed in the control groups (Fig. 3A). Rates of apoptosis and cell cycle distribution were determined by flow cytometry. Flow cytometric analysis indicated the number of apoptotic cells was markedly higher in the AA-treated groups compared with the control, and this increase was concentration-dependent (Fig. 3B). Additionally, the rate of apoptosis of the AA-treated groups were significantly higher compared with the control. Notably, an increase in apoptosis was observed in the sub-G1 population of SW480 and HCT116 cells treated with AA. There were also marked changes in cell cycle distribution with a decreased percentage of cells in the G1 phase and an increased percentage of cells in the G2/M and $\mathrm{S}$ phases, compared with the control (Fig. 3C) $(\mathrm{P}<0.05)$.

Effects of AA on epithelial-mesenchymal transition (EMT) marker protein expression in colon carcinoma cells. The expression of EMT-interrelated factors, as initiators of the metastatic cascade in the tumor cells, including vimentin, $\mathrm{N}$-cadherin and E-cadherin were evaluated in the present study (Fig. 4A). Consistent with the findings of the Transwell 
A
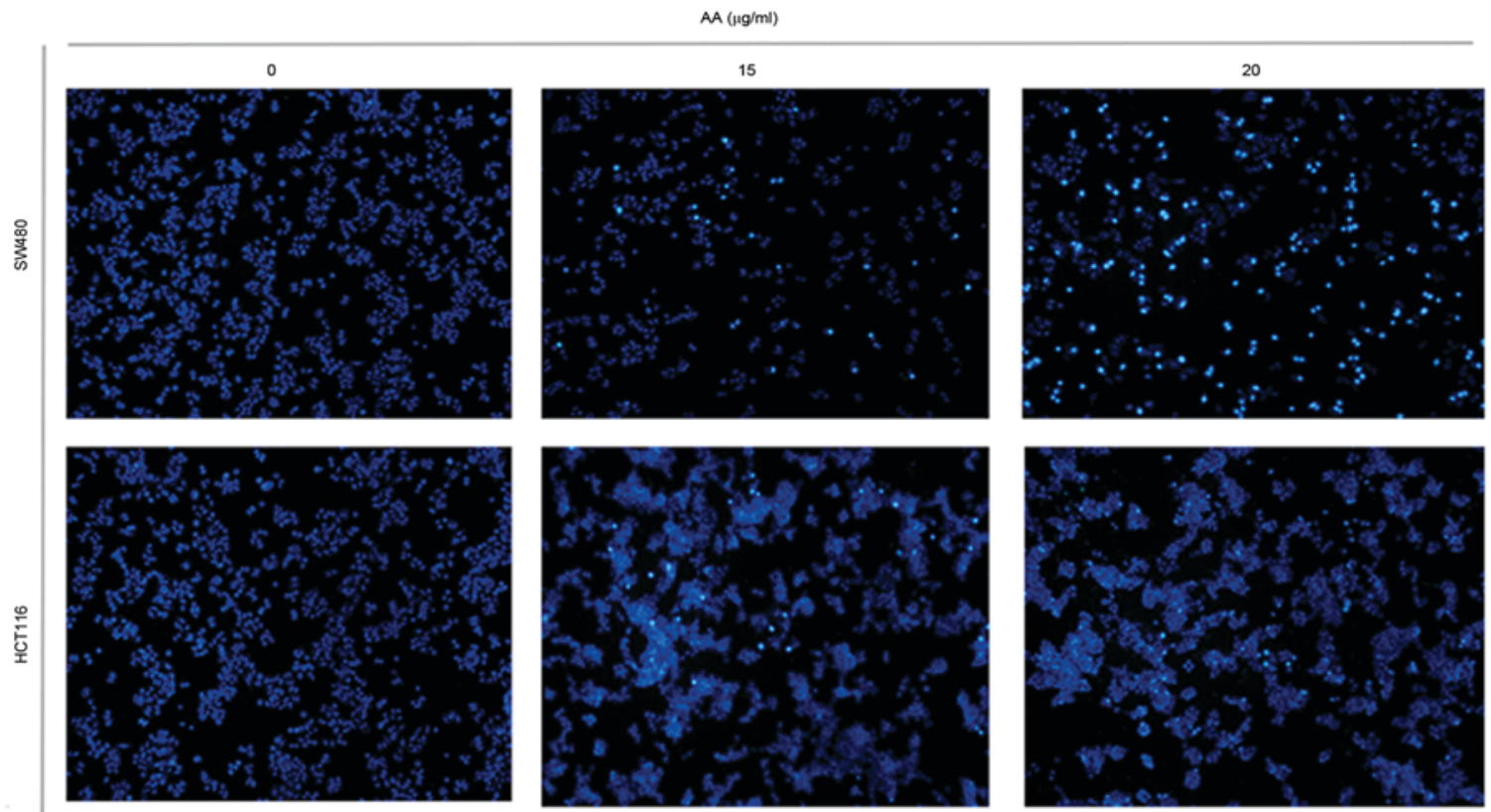

B

Conncentration $(\mu \mathrm{g} / \mathrm{ml})$
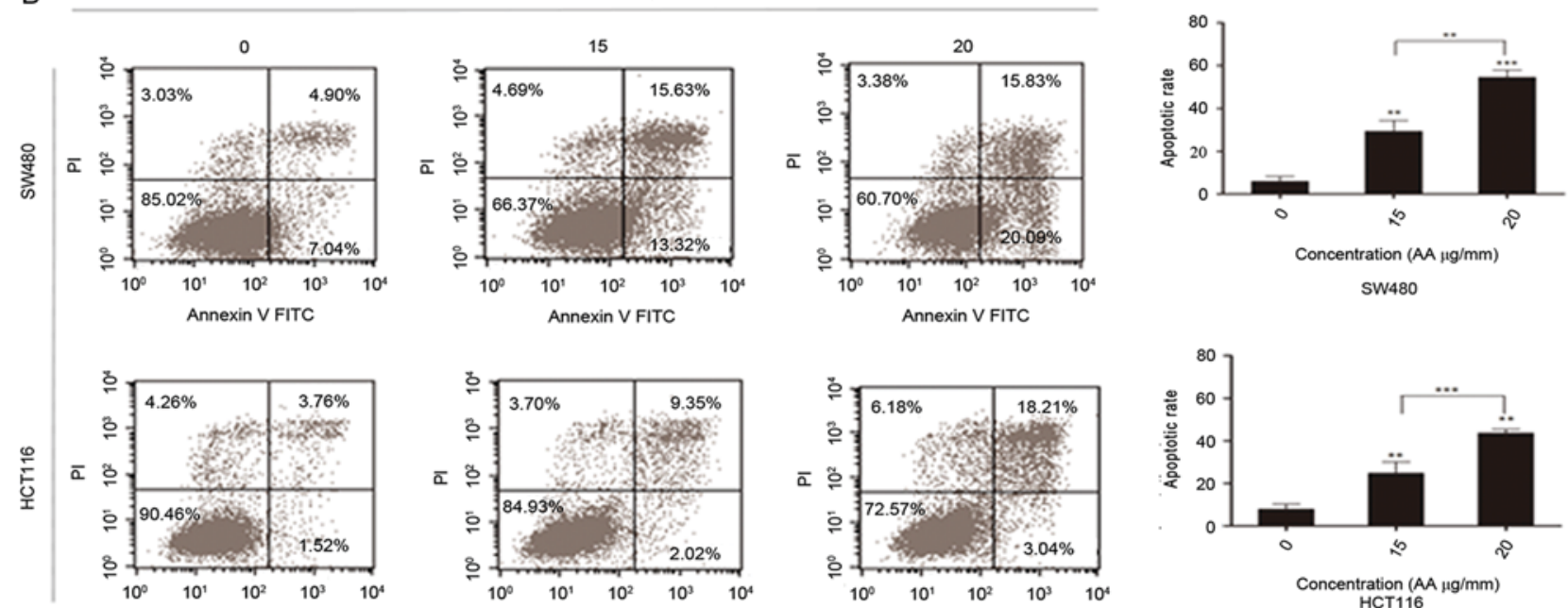

C

Conncentration $(\mu \mathrm{g} / \mathrm{ml})$
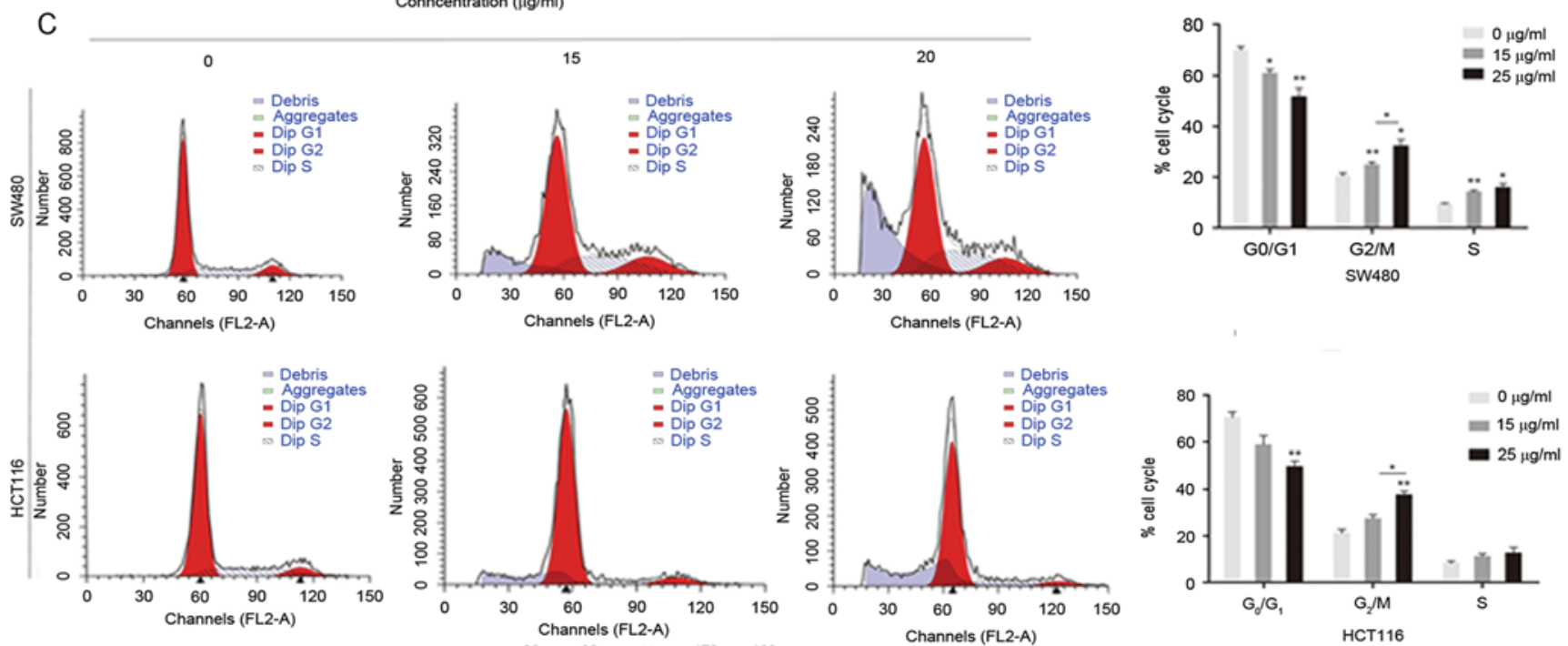

Figure 3. Asiatic acid induces apoptosis and $\mathrm{G}_{2}$ and $\mathrm{S}$ arrest in vitro. (A) Hoechst 33342 nuclear staining showed the efficacy of apoptosis (magnification, $\mathrm{x} 100$ ). (B) Annexin V/PI dual-immunofluorescence staining of cells treated with asiatic acid for $24 \mathrm{~h}$ revealed that the drug significantly increased apoptosis in cells (indicated by Annexin $\mathrm{V}^{+} / \mathrm{PI}^{+}$cells). (C) Flow cytometry data indicate $\mathrm{G} 2$ and M phase arrest in SW480 and HCT116 cells following incubation with asiatic acid for $24 \mathrm{~h}{ }^{*} \mathrm{P}<0.05,{ }^{* *} \mathrm{P}<0.01,{ }^{* * *} \mathrm{P}<0.01$ vs. control group. All results are expressed as the mean \pm standard error. FITC, fluorescein isothiocyanate; PI propidium iodide. 


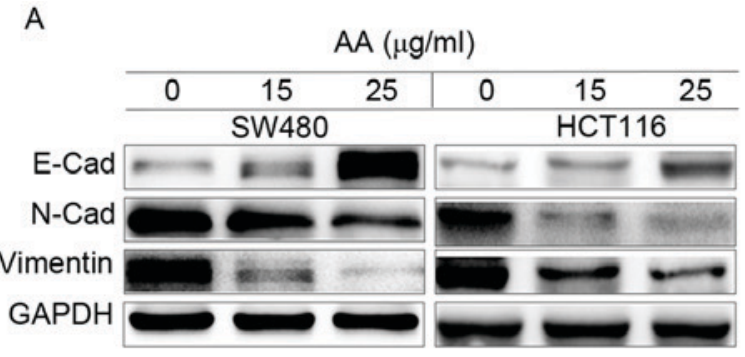

B

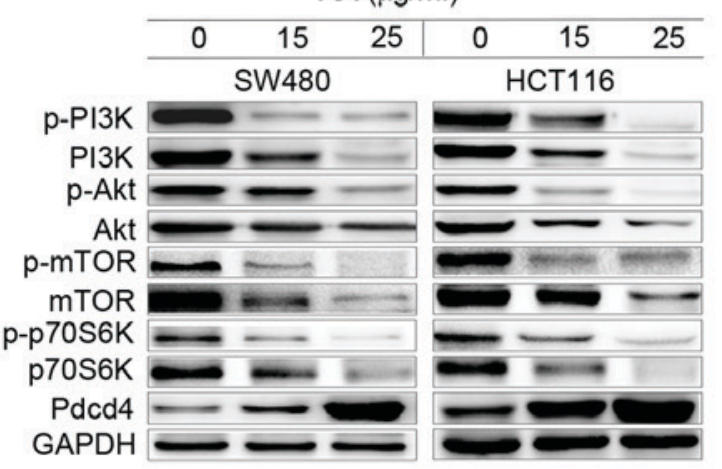

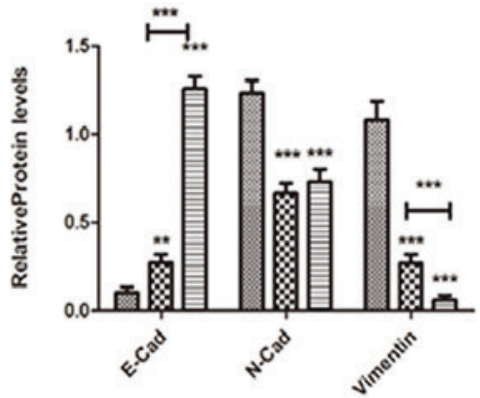
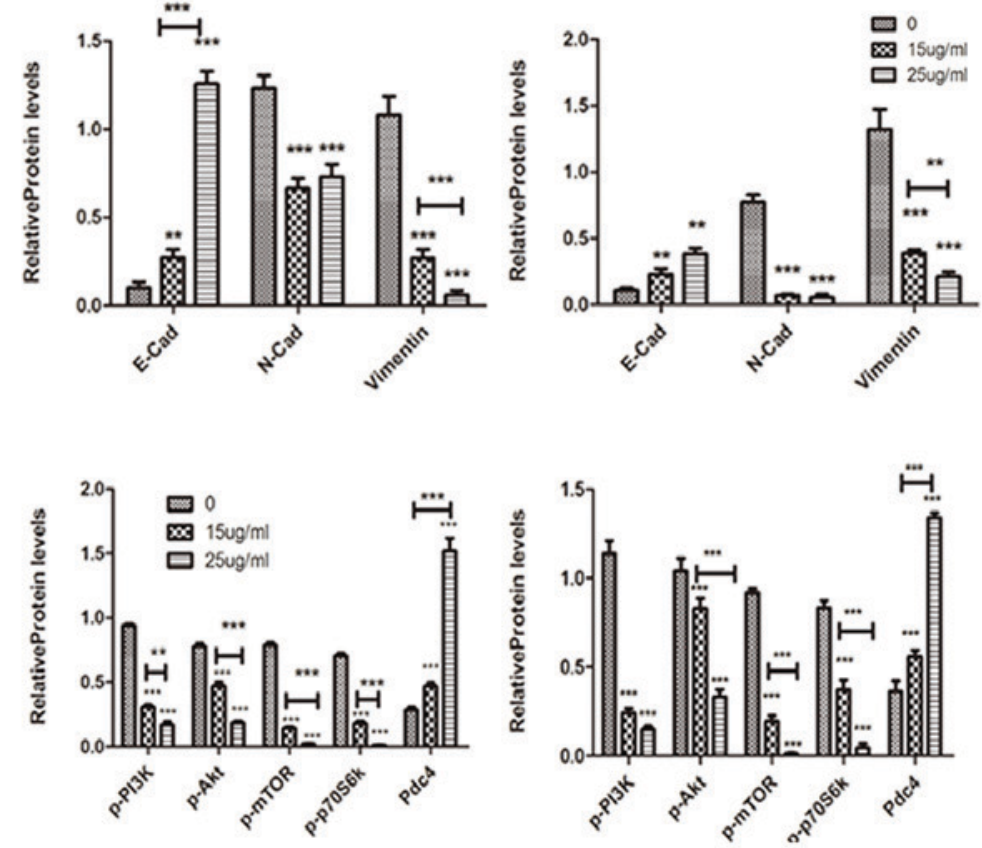

$\stackrel{\leftrightarrow}{\rightleftarrows}$

C
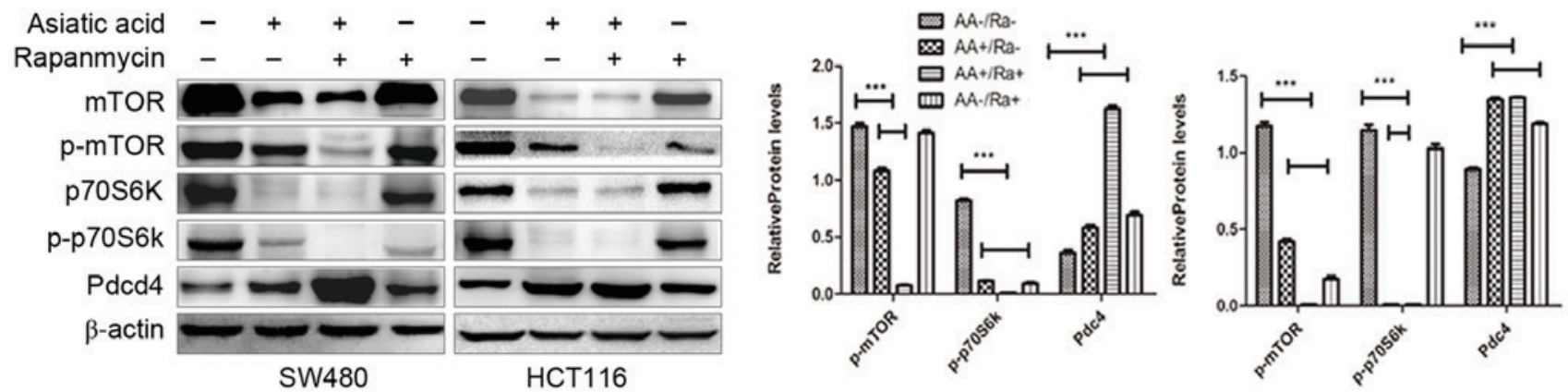

Figure 4. Western blot analysis of the effects of asiatic acid on the PI3K/Akt/mTOR/p70S6K/Pdcd4 signaling pathway in SW480 and HCT116 cells, and densitometric quantification of the blots compared with GAPDH/ $\beta$-actin. (A) The expression level of E-cadherin was increased while vimentin and N-cadherin expression was reduced. (B) The results showed downregulation of p-PI3K, p-Akt, p-mTOR, p-p70S6K and upregulation of Pdcd4. (C) Pretreatment with asiatic acid and rapamycin further decreased the expression of mTOR and p70S6K and increased the expression of Pdcd4. ${ }^{* * *} \mathrm{P}<0.01,{ }^{* * *} \mathrm{P}<0.001$. Asterisks alone indicate comparison of the control group with $15 \mu \mathrm{g} / \mathrm{ml}, 25 \mu \mathrm{g} / \mathrm{ml} \mathrm{AA}$, respectively. The underlined asterisks indicate a comparison between $15 \mu \mathrm{g} / \mathrm{ml} \mathrm{AA}$ and $25 \mu \mathrm{g} / \mathrm{ml}$ AA. PI3K, phosphoinositide 3-kinase; mTOR, mammalian target of rapamycin; p70S6K, ribosomal protein S6 kinase $\beta-1$; Pdcd4, programmed cell death protein 4; p, phosphorylated; AA, asiatic acid; Ra, rapamycin.

migration assay, it was observed that the level of E-cadherin expression was increased, while the expression of vimentin and $\mathrm{N}$-cadherin was reduced in the AA-treated groups. These results indicated that $\mathrm{AA}$-induced inhibition on migration in colon carcinoma cells may be associated with EMT.

AA meditates anticancer effects by regulating Pdcd4 via the PI3K/Akt/mTOR/p70S6K signaling pathway. The $\mathrm{PI} 3 \mathrm{~K} / \mathrm{Akt} / \mathrm{mTOR} / \mathrm{p} 70 \mathrm{~S} 6 \mathrm{~K}$ signaling pathway is one of the major pathways, which regulate proliferation, apoptosis and migration of cancer cells (13). Therefore, whether AA affects this pathway in colon carcinoma cells was investigated. As shown in Fig. 4B, treatment with AA markedly decreased the level of p-PI3K, p-Akt (Ser473), p-mTOR and p-p70S6K in a concentration dependent manner.

Additionally, the expression of Pdcd4 protein, downstream factor of p70S6K, was increased following treatment with
AA. The mTOR inhibitor rapamycin was subsequently used to investigate whether the PI3K/Akt/mTOR/p70S6K signaling pathway is involved in the proliferation, migration and apoptosis of colon cancer cells. It was observed that pre-treating cells with AA and rapamycin further decreased the expression of mTOR and p70S6K, and increased the expression of Pdcd4, compared with untreated cells (Fig. 4C). This finding suggests that AA partially exerts anticancer effect by regulating Pdcd4 via the $\mathrm{PI} 3 \mathrm{~K} / \mathrm{Akt} / \mathrm{mTOR} / \mathrm{p} 70 \mathrm{~S} 6 \mathrm{~K}$ signaling pathway in colon cancer cells.

\section{Discussion}

In the present study, a novel role for AA on antitumor activity of colon cancer cells was revealed. It was demonstrated that AA was able to induce apoptosis and cell cycle arrest of colon carcinoma cells. Additionally, AA was able to modulate the expression of EMT marker proteins colon carcinoma cells. 
The expression of PI3K, Akt, mTOR, p70S6K total protein and phosphorylated proteins in AA-treated colon carcinoma cells was significantly reduced compared with the control group. This is in contrast to the upregulation of Pdcd4 expression observed in the AA-treated cells compared to the control group. This suggests that AA induced apoptosis by partially regulating Pdcd4 through the $\mathrm{PI} 3 \mathrm{~K} / \mathrm{Akt} / \mathrm{mTOR} / \mathrm{p} 70 \mathrm{~S} 6 \mathrm{~K}$ signaling pathway.

AA has been reported to have an essential role in apoptosis, survival and proliferation in various types of carcinoma, including human hepatoma, breast cancer, non-small cell lung cancer cells, prostate cancer, glioblastoma, human melanoma, multiple myeloma, B-cell lymphoma and neuroblastoma cells (14-18). The mechanisms of apoptosis primarily involve two signaling pathways: The mitochondrial death pathway and the cell death receptor pathway. Tang et al (19) previously demonstrated that AA is able to induce inhibition of growth of colon cancer cells and apoptosis through the mitochondrial death cascade. In the present study, it was found that AA was able to induce colon cancer cell growth and apoptosis by regulating the inhibition of the PI3K/Akt/mTOR/p70S6K signaling pathway, therefore suggesting a new potential mechanism for the effect of AA on apoptosis of colon carcinoma cells. Furthermore, it was indicated that AA may inhibit proliferation and migration of colon cancer cells.

As a critical event in the development of carcinoma cells, EMT, is a process whereby epithelial cells first lose cell-cell adhesion and cell polarity, followed by an increase in migratory and invasive properties to become mesenchymal stem cells $(20,21)$. E-cadherin, N-cadherin and vimentin are three important promoters, which mediate migration and invasion of cancer cells through a number of signaling pathways $(22,23)$. Therefore, the present study investigated the expression of EMT-associated factors. As expected, AA markedly increased the level of E-cadherin and decreased the levels of $\mathrm{N}$-cadherin and vimentin in SW480 and HCT116, indicating the involvement of EMT in AA-induced inhibition of colon carcinoma cell migration.

$\mathrm{PI} 3 \mathrm{~K} / \mathrm{Akt} / \mathrm{mTOR} / \mathrm{P} 70 \mathrm{~S} 6 \mathrm{~K}$ is an important signaling pathway, which regulates progression in numerous tumors (24). This pathway controls cell proliferation, growth, translation, migration and survival, and over-activation of the signaling pathway is associated with poor prognosis (24). There are a number of anticancer drugs, which mediate anticancer activity via the PI3K/Akt/mTOR/p70S6K axis. For example, by targeting the insulin-like growth factor 1 receptor, growth and metastasis can be significantly inhibited through suppression of the PI3K/Akt/mTOR/p70S6K signaling pathway (25).

In addition, bone morphogenetic protein 9 has been shown to inhibit the proliferation and migration of breast cancer cells, and it was demonstrated that the PI3K/Akt/mTOR/p70S6K signaling pathway was involved in this process (25). Furthermore, activation of the PI3K/Akt/mTOR/p70S6K signaling pathway has been shown to be involved in S100A4-induced viability and migration in CRC cells (26).

Pdcd4 is a novel tumor suppressor protein that inhibits protein synthesis by suppressing translation $(27,28)$. The PI3K/Akt/mTOR signaling pathway constitutively represses Pdcd4 expression in acute myelocytic leukemia. All-trans retinoic acid induces Pdcd4 through inhibition of the PI3K/Akt/mTOR signaling pathway (29). Pdcd4 has also been shown to inhibit invasion by activating activator protein-1 (30). Pdcd4 and PI3K/Akt/mTOR/p70S6K constitute an important pathway, which modulates multiple biological processes in carcinoma cells (31). A limited number of studies have focused on the association between the PI3K/Akt signaling pathway and cancer cells that exhibit increased expression of Pdc4, including colon carcinoma cells. Notably, the present study found that AA was able to inhibit the PI3K/Akt/mTOR signaling pathway, which leads to apoptosis, an increase in the level of Pdcd4 expression and inhibition of cell invasion.

Taken together, the findings suggest that AA modulates the PI3K/AKT/mTOR signaling pathway, which affects cell proliferation, growth, translation, migration and survival. To the best of our knowledge, the present study is the first to describe the induction of apoptosis by AA by regulating Pdcd4 through the inhibition of the PI3K/Akt/mTOR/p70S6K signaling pathway Although therapeutics for the treatment of colon carcinoma remains at infancy, the present study suggests that AA may be a novel drug.

\section{Acknowledgements}

The present study was supported by the National Natural Science Foundation of China (grant no. 81202430), Pearl River S and T Nova Program of Guangzhou (grant no. 2014J2200092) and the Science and Technology Planning Project of Guangdong (grant no. 2014A020221012).

\section{References}

1. Brenner H, Kloor M and Pox CP: Colorectal cancer. Lancet 383: 1490-1502, 2014

2. Du C, Huang D, Peng Y, Yao Y, Zhao Y, Yang Y, Wang H, Cao L, Zhu WG and Gu J: 5-Fluorouracil targets histone acetyltransferases p300/CBP in the treatment of colorectal cancer. Cancer Lett 400: 183-193, 2017.

3. Woo IS and Jung YH: Metronomic chemotherapy in metastatic colorectal cancer. Cancer Lett 400: 319-324, 2017.

4. Siegel R, Desantis C and Jemal A: Colorectal cancer statistics, 2014. CA Cancer J Clin 64: 104-117, 2014.

5. Weidle UH, Birzele F and Krüger A: Molecular targets and pathways involved in liver metastasis of colorectal cancer. Clin Exp Metastasis 32: 623-635, 2015.

6. Nasir MN, Habsah M, Zamzuri I, Rammes G, Hasnan J and Abdullah J: Effects of asiatic acid on passive and active avoidance task in male spraque-dawley rats. J Ethnopharmacol 134: 203-209, 2011.

7. Zhang X, Wu J, Dou Y, Xia B, Rong W, Rimbach G and Lou Y: Asiatic acid protects primary neurons against C2-ceramide-induced apoptosis. Eur J Pharmacol 679: 51-59, 2012.

8. Soo Lee Y, Jin DQ, Beak SM, Lee ES and Kim JA: Inhibition of ultraviolet-A-modulated signaling pathways by asiatic acid and ursolic acid in HaCaT human keratinocytes. Eur J Pharmacol 476: 173-178, 2003.

9. Lee YS, Jin DQ, Kwon EJ, Park SH, Lee ES, Jeong TC, Nam DH, Huh K and Kim JA: Asiatic acid, a triterpene, induces apoptosis through intracellular $\mathrm{Ca}^{2+}$ release and enhanced expression of p53 in HepG2 human hepatoma cells. Cancer Lett 186: 83-91, 2002.

10. Hsu YL, Kuo PL, Lin LT and Lin CC: Asiatic acid, a triterpene, induces apoptosis and cell cycle arrest through activation of extracellular signal-regulated kinase and p38 mitogen-activated protein kinase pathways in human breast cancer cells. J Pharmacol Exp Ther 313: 333-344, 2005.

11. AdtaniPN,Narasimhan M,Punnoose AM and Kambalachenu HR: Antifibrotic effect of Centella asiatica Linn and asiatic acid on arecoline-induced fibrosis in human buccal fibroblasts. J Investig Clin Dent 8, 2017. 
12. Wang L, Xu J, Zhao C, Zhao L and Feng B: Antiproliferative, cell-cycle dysregulation effects of novel asiatic acid derivatives on human non small cell lung cancer cells. Chem Pharm Bull (Tokyo) 61: 1015-1023, 2013.

13. Gurfinkel DM, Chow S, Hurren R, Gronda M, Henderson C, Berube C, Hedley DW and Schimmer AD: Disruption of the endoplasmic reticulum and increases in cytoplasmic calcium are early events in cell death induced by the natural triterpenoid Asiatic acid. Apoptosis 11: 1463-1471, 2006.

14. Thakor FK, Wan KW, Welsby PJ and Welsby G: Pharmacological effects of asiatic acid in glioblastoma cells under hypoxia. Mol Cell Biochem 430: 179-190, 2017.

15. Kavitha CV, Jain AK, Agarwal C, Pierce A, Keating A, Huber KM, Serkova NJ, Wempe MF, Agarwal R and Deep G: Asiatic acid induces endoplasmic reticulum stress and apoptotic death in glioblastoma multiforme cells both in vitro and in vivo. Mol Carcinog 54: 1417-1429, 2015.

16. Park BC, Bosire KO, Lee ES, Lee YS and Kim JA: Asiatic acid induces apoptosis in SK-MEL-2 human melanoma cells. Cancer Lett 218: 81-90, 2005.

17. Wu Q, Lv T, Chen Y, Wen L, Zhang J, Jiang X and Liu F: Apoptosis of HL-60 human leukemia cells induced by Asiatic acid through modulation of B-cell lymphoma 2 family proteins and the mitogen-activated protein kinase signaling pathway. Mol Med Rep 12: 1429-1434, 2015.

18. Xu MF, Xiong YY, Liu JK, Qian JJ, Zhu L and Gao J: Asiatic acid, a pentacyclic triterpene in Centella asiatica, attenuates glutamate-induced cognitive deficits in mice and apoptosis in SH-SY5Y cells. Acta Pharmacol Sin 33: 578-587, 2012

19. Tang XL, Yang XY, Jung HJ, Kim SY, Jung SY, Choi DY, Park WC and Park H: Asiatic acid induces colon cancer cell growth inhibition and apoptosis through mitochondrial death cascade. Biol Pharm Bull 32: 1399-1405, 2009.

20. Kiesslich T, Pichler M and Neureiter D: Epigenetic control of epithelial-mesenchymal-transition in human cancer. Mol Clin Oncol 1: 3-11, 2013.

21. Gheldof A and Berx G: Cadherins and epithelial-to-mesenchymal transition. Prog Mol Biol Transl Sci 116: 317-336, 2013.

22. Bao B, Wang Z, Ali S, Kong D, Li Y, Ahmad A, Banerjee S, Azmi AS, Miele L and Sarkar FH: Notch-1 induces epithelial-mesenchymal transition consistent with cancer stem cell phenotype in pancreatic cancer cells. Cancer Lett 307: 26-36, 2011.

23. Zavadil J, Narasimhan M, Blumenberg $M$ and Schneider RJ Transforming growth factor-beta and microRNA: mRNA regulatory networks in epithelial plasticity. Cells Tissues Organs 185: $157-161,2007$
24. Syed DN, Afaq F, Sarfaraz S, Khan N, Kedlaya R, Setaluri V and Mukhtar H: Delphinidin inhibits cell proliferation and invasion via modulation of Met receptor phosphorylation. Toxicol Appl Pharmacol 231: 52-60, 2008.

25. Ren W, Liu Y, Wan S, Fei C, Wang W, Chen Y, Zhang Z, Wang T, Wang J, Zhou L, et al: BMP9 inhibits proliferation and metastasis of HER2-positive SK-BR-3 breast cancer cells through ERK1/2 and PI3K/AKT pathways. PLoS One 9: e96816, 2014.

26. Wang H, Duan L, Zou Z, Li H, Yuan S, Chen X, Zhang Y, Li X, Sun H, Zha H, et al: Activation of the PI3K/Akt/mTOR/p70S6K pathway is involved in S100A4-induced viability and migration in colorectal cancer cells. Int J Med Sci 11: 841-849, 2014.

27. Wen YH, Shi X, Chiriboga L, Matsahashi S, Yee H and Afonja O: Alterations in the expression of PDCD4 in ductal carcinoma of the breast. Oncol Rep 18: 1387-1393, 2007.

28. Afonja O, Juste D, Das S, Matsuhashi S and Samuels HH: Induction of PDCD4 tumor suppressor gene expression by RAR agonists, antiestrogen and HER-2/neu antagonist in breast cancer cells. Evidence for a role in apoptosis. Oncogene 23: 8135-8145, 2004.

29. Leupold JH, Yang HS, Colburn NH, Asangani I, Post S and Allgayer H: Tumor suppressor Pdcd4 inhibits invasion/intravasation and regulates urokinase receptor (u-PAR) gene expression via Sp-transcription factors. Oncogene 26: 4550-4562, 2007.

30. Yang HS, Jansen AP, Nair R, Shibahara K, Verma AK, Cmarik JL and Colburn NH: A novel transformation suppressor, Pdcd4, inhibits AP-1 transactivation but not NF-kappaB or ODC transactivation. Oncogene 20: 669-676, 2001.

31. Vikhreva PN, Shepelev MV and Korobko IV: mTOR-dependent transcriptional repression of Pdcd4 tumor suppressor in lung cancer cells. Biochim Biophys Acta 1839: 43-49, 2014.

This work is licensed under a Creative Commons

Attribution-NonCommercial-NoDerivatives 4.0 International (CC BY-NC-ND 4.0) License. 